Jurnal Health Sains: p-ISSN: 2723-4339 e-ISSN: 2548-1398

Vol. 2, No. 3, Maret 2021

\title{
UJI TOKSISITAS AKUT EKSTRAK ETANOL UMBI BIT (BETA VULGARIS L.) DENGAN METODE BSLT (BRINE SHRIMP LETHALITY TEST)
}

\section{Fauzy Arif Budiman dan Febri Hidayat}

Institut Sains dan Teknologi Al-Kamal (ISTA) Jakarta, Indonesia

Email: fauzyarif25@gmail.com dan febri_hidayat@yahoo.com

\begin{tabular}{l} 
ARTIKEL INFO \\
\hline Tanggal diterima: 5 Maret \\
2021 \\
Tanggal direvisi: 15 Maret \\
2021 \\
Tanggal disetujui: 25 Maret \\
2021
\end{tabular}

Keywords:

acute toxicity test; beetroot; artemia salina leach, bslt method

\begin{abstract}
Toxicity test is a preliminary test carried out to determine the toxic effects and threshold of the use of a plant as a medicine. Beetroot (Beta vulgaris L.) including the Chenopodiaceae family. Beet tuber is known to contain secondary metabolites of compounds such as flavonoids and phenolics. The purposed of this study was to determine the potential for acute toxicity of ethanol extract of beet tuber (Beta vulgaris L.) to Artemia salina Leach larvae using the BSLT method (Brine Shrimp Lethality Test) as indicated by the LC50 value. This experimental study used 180 Artemia salina Leach larvae which were divided into 1 negative control and 5 groups of extract concentration series, each consisting of 10 larvae with replication 3 times for each treatment. The concentrations of extracts were 1000, 500, 200, 100 and $50 \mathrm{ppm}$, respectively. The result of the observation is that larvae die 24 hours after administration of extract. The results of the probit analysis showed the LC50 value of beetroot ethanol extract (Beta vulgaris L.) was $239.82 \mathrm{ppm}$. This shows that the ethanol extract of beet tuber (Beta vulgaris L.) has the potential for acute toxicity to Artemia salina Leach larvae according to the BSLT method which is indicated by the value LC50< from $1000 \mathrm{ppm}$.
\end{abstract}

\begin{abstract}
ABSTRAK
Uji toksisitas merupakan suatu uji pendahuluan yang dilakukan untuk mengetahui efek toksik dan ambang batas penggunaan suatu tumbuhan sebagai obat. Umbi bit (Beta vulgaris L.) termasuk famili Chenopodiaceae. Umbi bit diketahui mengandung metabolit sekunder senyawa seperti flavonoid dan fenolik. Tujuan penelitian ini adalah untuk mengetahui potensi toksisitas akut ekstrak etanol umbi bit (Beta vulgaris L.) terhadap larva Artemia salina Leach dengan metode BSLT (Brine Shrimp Lethality Test) yang ditunjukkan dengan nilai $\mathrm{LC}_{50}$. Penelitian eksperimental ini menggunakan 180 ekor larva Artemia salina Leach yang dibagi menjadi 1 kontrol negatif dan 5 kelompok seri konsentrasi ekstrak, masing-masing terdiri dari 10 ekor larva dengan replikasi 3 kali untuk tiap perlakuan. Konsentrasi ekstrak berturut-turut adalah 1000, 500, 200, 100 dan $50 \mathrm{ppm}$. Hasil pengamatan adalah terhadap larva
\end{abstract}


Kata Kunci:

uji toksisitas akut; umbi bit; artemia salina leach; metode bslt yang mati 24 jam setelah pemberian ekstrak. Hasil dari analisis probit menunjukkan nilai $\mathrm{LC}_{50}$ dari ekstrak etanol umbi bit (Beta vulgaris L.) adalah $239.82 \mathrm{ppm}$. Hal ini menunjukkan bahwa ekstrak etanol umbi bit (Beta vulgaris L.) memiliki potensi toksisitas akut terhadap larva Artemia salina Leach menurut metode BSLT yang ditunjukkan dengan nilai $\mathrm{LC}_{50}<$ dari 1000 ppm.
Coresponden Author:

Email: fauzyarif25@gmail.com Artikel dengan akses terbuka dibawah lisensi

\section{Pendahuluan}

Bit merupakan salah satu bahan pangan yang sangat bermanfaat. Salah satu manfaatnya adalah memberikan warna alami dalam pembuatan produk pangan. Pigmen yang terdapat pada bit merah adalah betalain (Setiawan et al., 2015). Betalain merupakan golongan antioksidan. Pigmen betalain sangat jarang digunakan dalam produk pangan dibanding- kan dengan antosianin dan betakaroten (Putri, 2016). Kandungan vitamin dan mineral yang ada dalam bit merah seperti vitamin B dan kalsium, fosfor, nutrisi, besi merupakan nilai lebih dari penggunaan bit merah. Antioksidan merupakan substansi yang diperlukan tubuh untuk menetralisir radikal bebas dan mencegah kerusakan yang ditimbulkan olehradikal bebas dengan melengkapi kekurangan elektron yang memiliki radikal bebas (Hasanan, 2015). Antioksidan akan menghambat terjadinya reaksi berantai dari pembentukan radikal bebas yang dapat menimbulkan stres oksidatif. Antioksidan banyak terdapat pada buah-buahan dan sayursayuran (Wahyuni, 2011). Nilai pH untuk betalain adalah $\mathrm{pH} 4-6$. Antioksidan dari bit merah juga mempengaruhi oleh suhu dan pH (Timur, 2019).

Indonesia merupakan salah satu negara dengan kekayaan hayati terbesar yang memiliki lebih dari 30.000 spesies tanaman tingkat tinggi. Hingga saat ini tercatat 7.000 spesies tanaman telah diketahui khasiatnya namun kurang dari 300 tanaman yang digunakan sebagai bahan baku industri farmasi secara regular (Saifuddin A, Rahayu, 2011).

Salah satu tanaman yang banyak dikenal secara luas oleh masyarakat Indonesia adalah tanaman umbi bit. Umbi bit (Beta vulgaris L.) merupakan tanaman yang berumur pendek dan berbentuk akar yang mirip umbi-umbian dari famili Chenopodiaceae (Rahmawati, 2016). Umbi bit juga banyak di jumpai di Eropa dan sebagian Asia serta Amerika. Di Indonesia sendiri umbi bit dibudidayakan di pulau Jawa, terutama Cipanas, Lembang, Pangalengan dan Batu. Ciri fisik jenis umbi bit adalah umbinya berbentuk bulat seperti kentang dengan warna merah-ungu gelap, tinggi hanya berkisar 1-3 meter, dan apabila dipotong buahnya akan terlihat garis putihputih dengan warna merah muda (Wibawanto et al., 2014). Umbi bit mengandung vitamin C yang cukup tinggi sehingga dapat digunakan sebagai antioksidan yang dapat mencegah penyakit kanker. selain antioksidan umbi bit juga memiliki komponen utama yaitu pigmen betasianin yang memberikan warna merah keunguan (Wibawanto et al., 2014).

Uji toksisitas merupakan suatu uji pendahuluan yang dilakukan untuk mengetahui efek toksik dan ambang batas penggunaan suatu tumbuhan sebagai obat 
(Tampungan, 2011). Bahaya akibat pemaparan suatu zat pada manusia dapat diketahui dengan mempelajari efek kumulatif, dosis yang dapat menimbulkan efek toksik pada manusia yang umumnya informasi tersebut dapat diperoleh dari percobaan dengan hewan uji (Badan Pengawas, 2014). Uji toksisitas dengan menggunakan Larva udang Artemia salina Leach salah satu hewan uji toksisitas disebut metode pengujian BSLT (Brine Shrimp Lethality Test) dianggap memiliki korelasi daya sitotoksik senyawa antikanker, sifat-sifat sitotoksik yang dapat diketahui berdasarkan jumlah kematian larva pada konsentrasi tertentu sehingga sering dilakukan untuk skrining awal pencarian senyawa antikanker dan metode ini dikenal metode yang cepat, mudah, murah, dan hasilnya dapat dipertanggung jawabkan (Harmita, 2008). Hewan uji larva Artemia salina Leach yang berusia 48 jam karena memiliki saluran pencernaan yang sudah terbentuk lengkap sehingga sensitif terhadap suatu zat yang dimasukkan dan larva Artemia salina Leach identik dengan sel kanker yang membelah secara mitosis (Wulandari, 2014). Bila bahan yang diuji memberikan efek toksik terhadap larva udang, maka hal ini merupakan indikasi awal dari efek farmakologi yang terkandung dalam bahan tersebut.

\section{Metode Penelitian}

1. Ekstraksi Sampel

Mula-mula wadah maserasi dicuci bersih, keringkan dan dibilas dengan etanol 70\%. Sampel (500 gram) direndam dalam etanol $70 \%$ dengan perbandingan 5;1 (500 gram sampel : 1 liter etanol 70\%) dengan sesekali dikocok. Proses perendaman ini berlansung selama 3 hari. Kemudian dilanjutkan dengan proses penyaringan, maserat yang diperoleh diuapkan pelarutnya menggunakan rotary evaporator hingga diperoleh ekstrak kental.
2. Uji Fitokimia

Pengujian alkaloid dengan menggunakan pereaksi mayer dan dragendroff, pengujian saponin dengan menggunakan air panas dan $\mathrm{HCl} 1 \mathrm{~N}$, pengujian flavonoid dengan menggunakan $\mathrm{Mg}$ dan $\mathrm{HCl}$ pekat, pengujian tanin dengan menggunakan air panas dan $\mathrm{HCl} 1 \mathrm{~N}$, pengujian steroid dengan menggunakan $10 \% \mathrm{~K} 2 \mathrm{CrO} 4$, dan yang terakhir pengujian fenolik dengan menggunakan $\mathrm{FeCl} 31 \%$.

3. Penetasan Artemia salina Leach

Penetasan Artemia dilakukan dalam sebuah aquarium yang telah tersedia air laut buatan secukupnya. Kemudian taburkan kista Artemia secukupnya. Berikan aerator dan penerangan lampu untuk mempercepat perangsangan Artemia, serta diamkan selama 24 jam.

4. Penyiapan Sampel Uji

Larutan induk dibuat dengan melarutkan $250 \mathrm{mg}$ dan tambahkan aquadest sampai batas labu ukur $250 \mathrm{ml}$. sampel yang akan diuji disiapkan pada konsentrasi 1000, 500, 200, 100 dan 50 ppm. Sebagai kontrol negatif tanpa larutan uji.

5. Uji Toksisitas Akut Metode BSLT Sebanyak 10 larva Artemia dalam $10 \mathrm{ml}$ air laut buatan dimasukkan ke dalam vial uji, kemudian ditambahkan $1 \mathrm{ml}$ larutan sampel. Untuk setiap konsentrasi dilakukan 3 kali pengulangan. Sebagai kontrol negatif tambahkan air laut buatan dan larva Artemia.pengamatan dilakukan selama 24 jam dengan menghitung jumlah larva Artemia yang sudah mati dan masih hidup, dengan bantuan lup.

6. Analisis Data

Nilai LC50 ditentukan secara perhitungan metode manual dan statistik melalui persamaan regresi linier sederhana (sumbu $\mathrm{x}$ ditransformasi ke bentuk logaritma (log konsentrasi), sedangkan sumbu y adalah \% mortalitas, dengan 
bantuan program Microsoft office excel 2010.

\section{Hasil dan Pembahasan}

1. Hasil Uji Fitokimia

\section{Tabel 1}

Hasil Uji Fitokimia Ekstrak Etanol Umbi bit

\begin{tabular}{clc}
\hline No & \multicolumn{1}{c}{$\begin{array}{c}\text { Jenis } \\
\text { Pengujian }\end{array}$} & Hasil Pengujian \\
\cline { 2 - 2 } 1 & Alkaloid & + \\
\hline 2 & Saponin & ++ \\
\hline 3 & Flavonoid & ++ \\
\hline 4 & Tanin & + \\
\hline 5 & Steroid & ++ \\
\hline 6 & Fenolik & ++ \\
\hline
\end{tabular}

Keterangan:

$(++)$ Intensitas sedang

(+) Intensitas rendah

Ekstrak etanol umbi bit memiliki kandungan alkaloid, saponin, flavonoid, tanin, steroid, dan fenolik.

2. Hasil Uji Toksisitas Akut Ekstrak Etanol Umbi bit Dengan Metode BSLT

Jumlah kematian larva Artemia salina Leach pada setiap vial uji dalam berbagai konsentrasi ekstrak etanol umbi bit disajikan pada Tabel 1. Dari Tabel 1 tersebut dapat diketahui bahwa berbagai konsentrasi ekstrak etanol umbi bit pada percobaan ini memperlihatkan pengaruh yang berbeda terhadap kematian larva Artemia salina Leach.

\section{Tabel 2}

Hasil Uji Toksisitas Akut Dengan Metode BSLT

\begin{tabular}{ccccccc}
\hline Perlakuan & $\begin{array}{c}\mathbf{1 0 0 0} \\
\mathbf{p p m}\end{array}$ & $\begin{array}{c}\mathbf{5 0 0} \\
\mathbf{p p m}\end{array}$ & $\begin{array}{c}\mathbf{2 0 0} \\
\mathbf{p p m}\end{array}$ & $\begin{array}{c}\mathbf{1 0 0} \\
\mathbf{p p m}\end{array}$ & $\begin{array}{c}\mathbf{5 0} \\
\mathbf{p p m}\end{array}$ & $\begin{array}{c}\text { Kontrol } \\
\text { Negatif }\end{array}$ \\
\cline { 2 - 5 } & 9 & 8 & 4 & 2 & 1 & 0 \\
\hline $\mathbf{2}$ & 9 & 7 & 4 & 2 & 1 & 0 \\
\hline $\mathbf{3}$ & 9 & 8 & 3 & 2 & 1 & 0 \\
\hline$\sum$ & $\mathbf{2 7}$ & $\mathbf{2 3}$ & $\mathbf{1 1}$ & $\mathbf{6}$ & $\mathbf{3}$ & $\mathbf{0}$ \\
\hline
\end{tabular}

Tabel 3

Perhitungan Nilai $\mathrm{LC}_{50}$

\begin{tabular}{cccc}
\hline $\begin{array}{c}\text { Konsentras } \\
\mathbf{i} \\
(\mathbf{p p m})\end{array}$ & $\begin{array}{c}\text { Mortalita } \\
\mathbf{s}\end{array}$ & $\begin{array}{c}\text { Log } \\
\text { Konsentras } \\
\mathbf{i} \\
(\mathbf{x})\end{array}$ & $\begin{array}{c}\text { Nilai } \\
\text { Probi } \\
\mathbf{t} \\
(\mathbf{y})\end{array}$ \\
\hline $\mathbf{1 0 0 0}$ & 9 & 3 & 6.28 \\
\hline $\mathbf{1 0 0 0}$ & 9 & 3 & 6.28 \\
\hline $\mathbf{1 0 0 0}$ & 9 & 3 & 6.28 \\
\hline $\mathbf{5 0 0}$ & 8 & 2.69 & 5.84 \\
\hline $\mathbf{5 0 0}$ & 7 & 2.69 & 5.52 \\
\hline $\mathbf{5 0 0}$ & 8 & 2.69 & 5.84 \\
\hline $\mathbf{2 0 0}$ & 4 & 2.30 & 4.75 \\
\hline $\mathbf{2 0 0}$ & 4 & 2.30 & 4.75 \\
\hline $\mathbf{2 0 0}$ & 3 & 2.30 & 4.48 \\
\hline $\mathbf{1 0 0}$ & 2 & 2 & 4.16 \\
\hline $\mathbf{1 0 0}$ & 2 & 2 & 4.16 \\
\hline $\mathbf{1 0 0}$ & 2 & 2 & 4.16 \\
\hline $\mathbf{5 0}$ & 1 & 1.69 & 3.72 \\
\hline $\mathbf{5 0}$ & 1 & 1.69 & 3.72 \\
\hline $\mathbf{5 0}$ & 1 & 1.69 & 3.72 \\
\hline$\sum$ & - & $\mathbf{3 5 . 0 4}$ & $\mathbf{7 3 . 6 6}$ \\
\hline
\end{tabular}

Jumlah larva tiap vial uji dengan 3 kali replikasi adalah 30 ekor. Jumlah total larva Artemia salina Leach yang digunakan adalah 180 ekor larva. Total kematian diperoleh dengan menjumlahkan larva yang mati pada setiap konsentrasi. Data dianalisis dengan menggunakan metode secara dan Microsoft Office Excel 2010.

Perhitungan $\mathrm{LC}_{50}$ dengan metode manual yaitu dengan menggunakan rumus rumus:

Nilai Slope (m) dihitung dengan

$$
\frac{\sum(\mathrm{X}) \cdot \sum(\mathrm{Y})-\mathrm{n} \sum \cdot(\mathrm{X} . \mathrm{Y})}{\sum(\mathrm{X})^{2}-\mathrm{n} \sum(\mathrm{X})^{2}}=2.0323
$$
rumus:

Nilai Intersep (b) dihitung dengan

0.1632

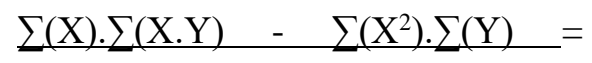

$$
\sum(\mathrm{X})^{2}-\mathrm{n} \sum(\mathrm{X})^{2}
$$

$\mathrm{Y}=2.0323 \mathrm{X}+0.1632$

$5=2.0323 \mathrm{X}+0.1632$

$4.8368=2.0323 \mathrm{X}$

$\mathrm{X}=2.3799$

$\mathrm{LC}_{50}=\operatorname{antilog} \mathrm{X}=\operatorname{antilog} 2.3799$

$=239.82 \mathrm{ppm}$. 
Perhitungan $\mathrm{LC}_{50}$ menggunakan Microsot Office Excel dengan membuat grafik untuk mendapatkan garis lurus $\mathrm{Y}=\mathrm{mX}+\mathrm{b}$. didapat hasil grafik sebagai berikut ini:

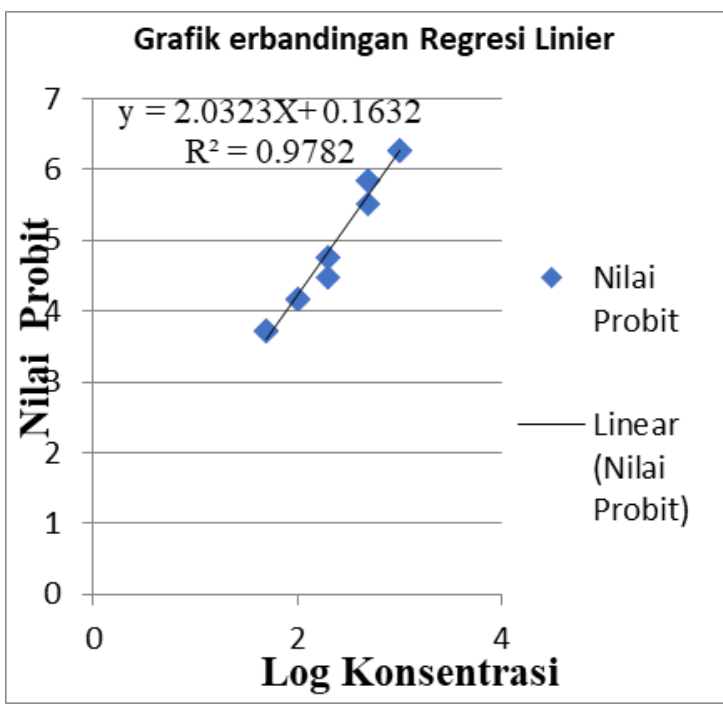

Dari grafik di atas menunjukkan log konsentrasi terhadap nilai probit yang didapat dari persen mortalitas larva udang. Didapat persamaan garis lurus $Y=2.0323 X+0.1632$. Dapat dilihat juga hubungan korelasi yang positif karena nilai $\mathrm{R}^{2}=0.9782$.

Ekstrak etanol umbi bit mempunyai potensi toksisitas akut (Hanifah, 2015). Hal tersebut berkaitan dengan ketiga senyawa yang berhasil diidentifikasi secara uji fitokimia yang terdapat dalam umbi bit yaitu golongan alkaloid, flavonoid dan fenolik. Ketiga golongan senyawa inilah yang berperan menyebabkan kematian pada larva Artemia salina Leach (Oktavia, 2017).

\section{Kesimpulan}

Penelitian ini menunjukkan bahwa ekstrak etanol umbi bit memiliki potensi toksisitas akut terhadap larva Artemia salina Leach menurut metode BSLT yang ditunjukkan dengan nilai LC50 < dari 1000 ppm.

\section{BIBLIOGRAFI}

Badan Pengawas. (2014). Peraturan Kepala Badan Pengawas Obat Dan Makanan Republik Indonesia Nomor 12 Tahun 2014 Tentang Persyaratan Mutu Obat Tradisional. Bpom.

Hanifah, N. Z. (2015). Uji Toksisitas Akut Ekstrak Metanol Daun Annona Muricata L Terhadap Larva Artemia Salina Leach Dengan Metode Brine Shrimp Lethality Test (Bslt). Jakarta: Fakultas Kedokteran Dan Ilmu Kesehatan Uin Syarif Hidayatullah, 2015.

Harmita, R. M. (2008). Buku Ajar Analisis Hayati. $E d, 3,1-2$.

Hasanan, N. (2015). Aktivitas Antioksidan Ekstrak Etanol Daun Salam. Pena Medika Jurnal Kesehatan, 5(1).

Oktavia, A. I. (2017). Etnobotani Tumbuhan Beracun Di Desa Ngadiwono Kecamatan Tosari Kabupaten Pasuruan. Universitas Brawijaya.

Putri, S. M. N. P. (2016). Identifikasi Dan Uji Antioksidan Senyawa Betasianin Dari Ekstrak Buah Bit Merah (Beta Vulgaris $L$ ). Universitas Negeri Semarang.

Rahmawati, N. (2016). Peningkatan Nilai Gizi Mi Basah Dengan Penambahan Tepung Kedelai Dan Umbi Bit Merah (Beta Vulgaris L. Var. Rubra L) Menggunakan Program Linier. Fakultas Teknik Unpas.

Saifuddin A, Rahayu, Y. H. (2011). Standarisasi Bahan Obat Alam. Graha Peraturan Ilmu.

Setiawan, M. A. W., Nugroho, E. K., \& Lestario, L. N. (2015). Ekstraksi Betasianin Dari Kulit Umbi Bit (Beta Vulgaris) Sebagai Pewarna Alami. Agric, 27(1), 38-43.

Tampungan, W. A. (2011). Uji Toksisitas 
Uji Toksisitas Akut Ekstrak Etanol Umbi Bit (Beta Vulgaris L.) dengan Metode Bslt (Brine

Ekstrak Batang Pinang Yaki (Areca

Test (Bslt).

Vestiaria) Pada Artemia Salina Leach.

Jurnal Bios Logos, 1(1).

Timur, M. F. (2019). Pengaruh Penambahan Konsentrasi Xhantan Gum Dan Sari Umbi Bit (Beta Vulgaris L.) Terhadap Mutu Sari Kedelai (Glycine Max L.). University Of Muhammadiyah Malang.

Wahyuni, R. (2011). Optimasi Pengolahan Kembang Gula Jelly Campuran Kulit Dan Daging Buah Naga Super Merah (Hylocereus Costaricensis) Dan Prakiraan Biaya Produksi. Teknologi Pangan: Media Informasi Dan Komunikasi Ilmiah Teknologi Pertanian, 1(1).

Wibawanto, N. R., Ananingsih, V. K., \& Pratiwi, R. (2014). Produksi Serbuk Pewarna Alami Bit Merah (Beta Vulgaris L.) Dengan Metode Oven Drying. Prosiding Snst Fakultas Teknik, 1(1).

Wulandari, F. (2014). Uji Toksisitas Akut Ekstrak Metanol Daun Mahkota Dewa (Phaleria Macrocarpa [Scheff.] Boerl.) Terhadap Larva Artemia Salina Leach Dengan Metode Brine Shrimp Lethality 